INTERNATIONAL JOURNAL OF MULTIDISCIPLINARY RESEARCH AND ANALYSis

ISSN(print): 2643-9840, ISSN(online): 2643-9875

Volume 04 Issue 12 December 2021

DOI: 10.47191/ijmra/v4-i12-15, Impact Factor: 6.072

Page No.- $1879-1885$

\title{
COVID-19 and intimate partner violence: Women "trapped" in the "shadow pandemic"
}

\author{
Zulaikatu Mustapha, MD, MSc, MPH${ }^{1}$, Shivaughn Hem-Lee-Forsyth, PhD, MPH, FRSPH ${ }^{2}$, \\ Hanna Bryant, MD $^{3}$ \\ ${ }^{1}$ Department of Business and Management, School of Arts and Sciences, St. George's University \\ 2,3 Department of Public Health and Preventive Medicine, School of Medicine, St. George's University
}

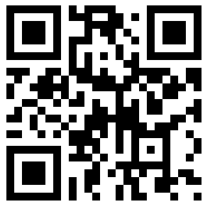

ABSTRACT: The United Nations (UN) defines domestic violence as behavioural patterns in a relationship to gain or maintain power and control over an intimate partner. Domestic violence compromises the physical, emotional, mental, and economic well-being of victims. In worst-case scenarios, domestic violence can result in the death of its victims. The advent of the COVID-19 pandemic has been accompanied by increased reports of domestic violence, primarily against women. The World Bank affirmed that before the COVID-19 pandemic, domestic violence was a global pandemic affecting 1 in 3 women in their lifetime -a staggering statistic. In contrast to the conspicuous nature of most pandemics, the domestic violence pandemic is silent and difficult to detect. Consequently, victims find themselves trapped in a shadow pandemic. The socio-ecological model was proposed to address this problem to achieve a durable and practical resolution. A narrative review method was employed to gather the literature. Articles published from 1995 to 2021 were searched using Google Scholar, PubMed, and Elsevier. Original research papers and articles highlighting the factors influencing the rise of domestic violence during COVID-19 were selected. Supplemental information was retrieved from the websites of international health agencies. After a complete review, 36 sources that met the inclusion criteria were selected. The research identified several significant drivers of domestic violence during the COVID-19 pandemic: economic hardship in the setting of social unrest; low socioeconomic status; low educational attainment; mental illness; family dysfunction; and substance abuse. Other added risk factors included the shutdown of usual safe havens to curtail virus spread and the societal tolerance of violence against women.

KEYWORDS: Intimate partner violence, domestic violence during COVID-19 lockdowns, violence against women, economic hardship and domestic violence, substance abuse and domestic violence, mental illness and domestic violence, domestic violence policy

\section{INTRODUCTION}

Domestic violence is a pervasive and indiscriminate global issue affecting women and children of diverse racial, socioeconomic, and cultural backgrounds. There is a challenge involving detecting and monitoring this type of violence due to its scope and restricted reporting. According to Bacchus et al. (2018), nearly $30 \%$ of all women globally who have been in a relationship have been victims of violence by their intimate partners. Domestic violence also has dire social and economic costs to individuals and societies. Recent research suggests that the COVID-19 pandemic has induced an upsurge in domestic violence, indirectly driving further economic and social crises (Sharma \& Borah, 2020) and spurring a potentially vicious cycle. The objective of this paper was to provide a comprehensive compilation and discussion of the factors contributing to the rise of domestic violence against women during the COVID-19 pandemic.

The economic cost of domestic violence is exorbitant. Some costs are incurred directly from lost productivity resulting from sick days and time off required by injured and recovering victims. Other costs accrue due to taxpayer funds being siphoned away from endeavours of priority to defray the costs of problems engendered by domestic violence. These costs are associated with health care visits, legal matters, housing expenses, and shelter resources. Moreover, domestic violence can exacerbate gender and economic inequality by compromising women's participation in the labour force, thereby widening the gender wage gap. Research on the impact of domestic violence on labour participation found a higher likelihood of unemployment, lower incomes, and reception of public assistance among women who reported abuse (Lloyd, 1997). In 2016, the United Nations (UN) 


\section{COVID-19 and intimate partner violence: Women "trapped" in the "shadow pandemic}

estimated the global cost of domestic violence at 1.5 trillion dollars (UN Women, 2016). This amount was more than half the estimated GDP of the entire African continent in 2019 - a prodigious price we pay for an inadequate response.

Socially, domestic violence can lead to far-reaching and devastating consequences, encompassing various adverse health outcomes of both physical and psychological nature (Bacchus et al., 2018). Physical and mental health issues can be precipitated by domestic violence, resulting in the worsening of the well-being and overall quality of life of victims (Parker, 2021). By extension, children under the guardianship of perpetrators and victims suffer enduring adverse consequences. Unfortunately, even mere observation of violence can negatively impact children's emotional and mental development. Research affirms that conduct disorder was three times more prevalent in children who witnessed severe domestic violence than their unexposed counterparts (Meltzer et al., 2009). Domestic violence coupled with other pandemic-engendered challenges can further amplify mental illness as an excessive societal burden. As previously mentioned, domestic violence can also diminish productivity and economic competitiveness, disrupting the overall progress of societies.

Even before lockdowns, domestic violence was an issue of concern in most nations across the globe. In 2010, Devries et al. (2013) discovered after scrutinizing data from 81 countries that one in three women aged 15 and above had experienced domestic violence. Regrettably, the emergence of the COVID-19 pandemic and the necessary mitigating measures implemented by most countries has led to a heightened scale of violence. A novel report affirmed a global increase in the rates of domestic violence in the wake of the coronavirus pandemic. The report cited a $300 \%$ rise in domestic violence in China, a $30 \%$ increase in France, and a 40-50\% surge in Brazil. In addition, the report indicated similar trends observed in Spain, Italy, and the United States (Campbell, 2020).

The rise of domestic violence due to the COVID-19 pandemic is disturbing but not unusual. Several research articles reveal a link between natural disasters and other precarious times with increased domestic violence. The COVID-19 pandemic, a biological disaster causing immense uncertainty, is no exception in its capacity to precipitate domestic violence. Gearhart et al. (2018) collected, compiled, and compared assault report data from Florida counties over nine years; reports of assaults increased during natural disasters and saw an exponential rise relative to the duration of exposure. The World Health Organisation (2021) also contends that violence against women tends to escalate during emergencies such as epidemics, citing stress, heightened economic difficulties, disruption of social and protective networks, and reduced access to services as contributing factors.

Given the enormous cost of domestic violence and its myriad of psychosocial complications, it is evident there is an acute need for its redress via galvanizing multisectoral advocacy efforts. Although a review of available literature revealed a preponderance of information on the subject, none of the established research has focused exclusively on a summary of factors contributing to the increased domestic violence since the start of the COVID-19 pandemic. However, delineating its key drivers is foundational to engendering practical and efficacious solutions. This research highlights the victim, perpetrator, economic, social, and policy risk factors leading to the rise in domestic violence during the COVID-19 pandemic.

\section{METHODOLOGY}

The literature was collected between March 2020-September 2021, using Google Scholar, PubMed, and Elsevier electronic databases. A narrative review method was deemed appropriate due to the novel and dynamic nature of the COVID-19 pandemic, permitting the acquisition of a general yet multifaceted perspective on an evolving, systemic issue. The databases Google Scholar, PubMed, and Elsevier were systematically surveyed for articles written in English from 1995 to 2021. The aim was to find original research papers that highlighted the factors influencing the rise of domestic violence during the COVID-19 pandemic. The following key terms were entered in various combinations: COVID-19 and the rise in domestic violence; the rise in domestic violence during COVID-19 pandemic; disasters and violence against women; pandemics and the rise of domestic violence; factors causing violence against women; factors contributing to the rise of domestic violence during the COVID-19 pandemic. Although multiple databases were explored, most of the research articles utilized for this study were retrieved from Google Scholar.

The inclusion criteria designated articles whose full texts were accessible and those published between 1995 and 2021. Generally, articles with a global approach to analyzing domestic violence amid the COVID-19 pandemic were preferred over those considered locally-focused. Also selected were research papers that offered insight into violence, its causes, risk factors, and the impact of social disruptions, such as the COVID-19 pandemic. The exclusion criteria omitted articles published in languages other than English and those that focused disproportionately on the impact of domestic violence on children. Also excluded were articles considered too narrowly focused, such as papers that heavily emphasized culture-specific contributors to domestic violence.

In the initial evaluation, 120 abstracts and titles were compiled from the various search engines. The abstracts of selected titles were subjected to further scrutiny, and duplicates were eliminated. The number of articles was reduced to 96 , of which the full texts of 60 were obtainable. Out of the 60 articles, 29 met the inclusion criteria and were included. In addition, the websites of global health organizations and non-governmental organizations, notably the World Health Organization (WHO) and the United 


\section{COVID-19 and intimate partner violence: Women "trapped" in the "shadow pandemic}

Nations (UN), were perused to gain supplementary information toward a global perspective on the issue. This search yielded an additional 7 articles. The evolving nature of the subject matter, and the methodology utilized allowed for a general preliminary perspective on the issue. Therefore, more extensive research needs to be carried out over a protracted duration using a systematic review method to eliminate bias and improve the robustness of the research findings.

\section{FINDINGS}

Assessment of the selected literature revealed that the factors that precipitated domestic violence against women during the COVID-19 pandemic could be categorized into five major themes. The delineated themes include victim risk factors, perpetrator risk factors, economic factors, social factors, and policy factors. Although these contributing components are introduced separately, they are intrinsically connected and influenced by reciprocal interactions.

\section{Victim risk factors}

Victim risk factors are traits, experiences and afflictions that expose victims to heightened domestic violence. The victim risk factors that were associated with the rise of domestic violence are as follows: being female (Lima et al., 2020); suffering from psychological stress (Usher et al., 2020); being entrapped in child marriage (International Women's Health Coalition, 2018); having a mental health illness (Sagar \& Hans, 2018); being afflicted with drug and alcohol abuse; illiteracy (Tadesse et al., 2021); having a partner who abuses substances (Tadesse et al., 2021); and a history of rape and abuse (Lima et al., 2020).

\section{Perpetrator risk factors}

Perpetrator risk factors are the inherent traits, experiences and afflictions that make perpetrators more prone to violence toward their partners. The perpetrator factors identified are as follows: being exposed to childhood abuse (WHO, 2021); low educational attainment (WHO, 2021); the presence of psychological stress exacerbated by pandemic-induced confining measures (Usher et al., 2020); mental illness (Campbell, 2020); emotional insecurity (Usher et al., 2020); toxic masculinity and possessing a controlling personality (WHO, 2021); and drug and alcohol abuse (WHO, 2021).

\section{Economic risk factors}

There were numerous economic factors responsible for the increase in domestic violence during the pandemic. These factors are as follows: poverty (Sharma and Borah, 2020); low income (Lloyd, 1997); unemployment (Lloyd, 1997); and job loss (Sharma and Borah, 2020). These economic factors negatively impact individuals' capacity to acquire necessities like food and shelter, eliciting added stress and precipitating domestic violence.

\section{Social risk factors}

Social factors refer to the structural and hierarchical elements inherent in families, cultures, and quotidian interactions that increase domestic violence rates. The social factors promoting domestic violence are as follows: increased societal tolerance towards acts of violence towards women (Tadesse et al., 2020); existing family dysfunction (Fegert et al., 2020); gender inequality (Rauhaus et al., 2020); increased isolation engendered by the pandemic (Campbell, 2020); and overcrowding resulting from lowincome living arrangements (Fisher et al., 2020).

\section{Policy risk factors}

Policy risk factors encompass the measures that have been taken to prioritize and control the pandemic. These factors include virus mitigation strategies such as social distancing and the implementation of lockdown orders (Usher et al., 2020). Another policy factor is shifting priorities towards curbing COVID-19 spread at the expense of all else. The shortfall of this action is the neglect of most other essential health care services. Indeed, a significant number of services and protective measures that were established to support victims of domestic violence, such as crisis lines; centres and shelters; and legal aid groups were put on hold or cancelled altogether once lockdown measures were instituted, worsening an already dire situation for victims with limited resources (Su et al., 2021).

\section{DISCUSSION}

Domestic violence is a highly complex issue comprising various inter-webbing, interdependent factors. Drivers of domestic violence during the COVID-19 pandemic are grouped into five general categories: individual risk factors, perpetrator risk factors, social factors, economic factors, and policy factors. These categories are dynamic and often interconnected. For instance, enduring financial hardships can lead to stress, heightening a person's propensity toward substance misuse and abuse. Substance abuse, in turn, increases a person's risk for becoming a victim and perpetrator alike, as evidenced in the literature (Sagar \& Hans, 2018). This scenario exemplifies the intricacies and challenges inherent in addressing domestic violence, and it also underscores the necessity of multisector and multi-stakeholder partnerships in redressing the problem. 


\section{COVID-19 and intimate partner violence: Women "trapped" in the "shadow pandemic}

Economic hardship, mental illness, and isolation were recurring subthemes. They are significant because each component independently can induce stress and compromise an individual's capacity to cope with life's challenges. Unfortunately, it is common for individuals to simultaneously possess more than one of these risk factors. Concurrent harbouring of multiple risk factors, which are often interconnected and mutually reinforcing, amplifies both the risk of victimization and violence perpetration. A lack of awareness of and accessibility to the appropriate channels for reporting might be another impediment to reporting abuse. This reality is of heightened concern in socially and economically disadvantaged communities, where victims are under-resourced at baseline and less likely to receive community support to report domestic violence incidents (Chipare, 2021). As a means of mitigating economic hardship during precarious times, policy should work toward installing financial safety nets to support members of society of lower socioeconomic status. This measure might be controversial politically, but the benefits are tremendous, and it certainly has the potential to reduce domestic violence and other societal maladies.

Substance abuse is another subtheme that repeatedly arose in the research. The findings suggest that alcohol and drug abuse increased the risk of both victimization and perpetration (Sagar \& Hans, 2018). However, it is overly simplistic to attribute the perpetration of violence to exclusively drugs and alcohol abuse. Other factors such as individual temperament and life experiences also influence a person's inclination toward substance abuse and violence. Nevertheless, there is no doubt that drugs and alcohol cause a decrease in restraint by impairing proper brain functioning. One study discovered that those who abuse alcohol had lowered inhibitions due to alcohol's impairment of the right frontotemporal portion of the inhibition network, decreasing a perpetrator's threshold for a violent outburst (Gan et al., 2014). This finding lends scientific credence to the notion of substance abuse-induced violence. It has also been confirmed that combating loneliness and coping with interpersonal difficulties are critical reasons people succumb to substance abuse (Mannes et al., 2015). The COVID-19 pandemic and the mitigation measures installed have exacerbated the contemporary loneliness epidemic and other hardships inherent in our increasingly solitary societies. Therefore, this finding, although disturbing, is undoubtedly intuitive.

According to research, the presence of a mental health disorder in victims - notably anxiety, depression, and posttraumatic stress disorder (PTSD) - has a bidirectional relationship with domestic violence (Sagar \& Hans, 2018). This link implies that women with mental health disorders are more prone to victimization, and abused women are more susceptible to mental illness. One probable reason for the victimization of those with mental illness includes the incapacitation caused by the illness, decreasing the likelihood of seeking assistance. Research has also shown that women who have been exposed to domestic violence are more vulnerable to an array of mental health issues such as PTSD, anxiety, depression and suicidal ideation (Parker, 2021). In addition, due to stigmatization, authorities fail to allocate adequate attention and support to address the complaints of those who have a mental illness (Parker, 2021). Research also reveals a higher preponderance of comorbid substance abuse among persons with severe mental illness (RachBeisel et al., 1999). This dual affliction consequently compounds the risk of victimization and perpetration of domestic violence, as substance use generates conditions in which victims become even more vulnerable and perpetrators are more likely to act without restraint. Understanding this dynamic is pivotal for developing an appropriate remedial strategy for female victims of domestic violence.

Lastly, to control the spread of the novel COVID-19 virus, governments around the globe monomaniacally focused on the virus at the expense of several other services deemed non-essential. These services included crisis lines, counselling, alternative housing, and shelters, which serve as crucial support systems and safe havens for victims. At the height of the pandemic, it may have seemed rational to channel more resources towards combating a global threat like COVID-19 at the expense of all else. However, this course of action has proven itself negligent in the long term. Like COVID-19, domestic violence is an existential crisis that, if not prioritized, can lead to deaths and long-lasting damage long after the pandemic is over.

\section{CONCLUSION}

This research aimed to delineate the factors that contributed to the rise of domestic violence during the COVID-19 pandemic. Domestic violence against women has certainly peaked during the COVID-19 pandemic, and the contributing factors are diverse, multifaceted, and interlinked. Therefore, viable and tenable solutions ought to target multiple root causes simultaneously. For success, a multi-stakeholder approach involving governmental, private, and citizen-led initiatives that actively engage with the problem at multiple levels is required. Additionally, due to the broad-reaching adverse effects of this issue, it might be appropriate to categorize domestic violence as an essential public health issue. The socio-ecological model of change was proposed as an effective method to target the problem at multiple levels.

On the intrapersonal level, guardians and teachers need to teach children, from a tender age, the importance of selfreliance, confidence and resisting peer pressure. As men comprise most perpetrators in domestic violence cases, boys and men ought to be encouraged to express their emotions in constructive ways. In addition, the mental health of children and young adults should be carefully assessed by caregivers toward early recognition of worrisome behaviours and the facilitation of professional 


\section{COVID-19 and intimate partner violence: Women "trapped" in the "shadow pandemic}

help before irreversible damage is done. Finally, the perils of drugs and alcohol should be made clear to children and adolescents using appropriate tools and avenues to mitigate future chances of abuse.

On the interpersonal level, guardians and caregivers need to model healthy relationship patterns with children and teenagers while engaging with them, equipping children and young adults with the requisite self-protection while preempting exploitation skills. Persons of all gender identities should be taught healthy ways of engaging with others in intimate relationships, although an emphasis should be placed on heterosexual males. Teachers should also monitor their wards for signs of maltreatment and abuse and promptly report to appropriate authorities when necessary. Furthermore, as a mechanism of modelling responsible behaviour to children and adolescents, guardians and caregivers should engage with intoxicants responsibly, and professional help should be sought in misuse and abuse cases. Ultimately, campaigns that create public awareness about domestic violence should be launched, emphasizing the crucial roles of ordinary citizens in mitigating the problem and encouraging community participation.

Organizations, governmental and non-governmental, should take a firm stance on domestic violence by sanctioning perpetrators and extending requisite support and leniency to victims. Organizations responsible for supporting domestic violence victims should be adequately staffed with personnel who are conversant with the intricacies of domestic violence to render appropriate support to the clients they serve. These organizations include law enforcement agencies, the judiciary, healthcare institutions, and organizations charged with protecting women and children. In particular, general and mental health practitioners alike should be encouraged to develop a routine practice of asking patients suffering from anxiety or depressive disorders about a history of domestic violence or abuse of any kind (Parker, 2021).

Policies that promote gender equality need to be engendered, enacted, and enforced at the community and societal levels. In addition, accommodative attitudes towards mistreatment and violence against women need to be dispelled through public education and awareness campaigns. Furthermore, punitive measures against perpetrators need to be established where absent and diligently enforced where they are existent. Finally, governmental and non-governmental organizations should use the findings in this paper to create novel policies and improve existing ones to remediate the "shadow pandemic" of domestic violence.

\section{REFERENCES}

1) Akel, M., Berro, J., Rahme, C., Haddad, C., Obeid, S., \& Hallit, S. (2021). Violence against women during COVID-19 pandemic. Journal of Interpersonal Violence, 088626052199795. https://doi.org/10.1177/0886260521997953

2) Bacchus, L. J., Ranganathan, M., Watts, C., \& Devries, K. (2018). Recent intimate partner violence against women and health: A systematic review and meta-analysis of cohort studies. BMJ Open, 8(7). https://doi.org/10.1136/bmjopen-2017019995

3) Bradbury-Jones, C., \& Isham, L. (2020). The pandemic paradox: The consequences of COVID-19 on domestic violence. Journal of Clinical Nursing, 29(13-14), 2047-2049. https://doi.org/10.1111/jocn.15296

4) Campbell, A. M. (2020). An increasing risk of family violence during the Covid-19 pandemic: Strengthening community collaborations to save lives. Forensic Science International: Reports, 2, 100089. https://doi.org/10.1016/j.fsir.2020.100089

5) Chipare, M. (2021). The hidden monster of domestic violence during the COVID-19 pandemic in resource-limited settings: A call to action. Medical Journal of Zambia, 48(1), 1-3.

6) Devries, K. M., Mak, J. Y., García-Moreno, C., Petzold, M., Child, J. C., Falder, G., Lim, S., Bacchus, L. J., Engell, R. E., Rosenfeld, L., Pallitto, C., Vos, T., Abrahams, N., \& Watts, C. H. (2013). The global prevalence of intimate partner violence against women. Science, 340(6140), 1527-1528. https://doi.org/10.1126/science.1240937

7) Domestic Abuse and Covid-19: The Rising Cases of Women ... (n.d.). https://nenow.in/opinion/domestic-abuse-and-covid19-the-rising-cases-of-women-fighting-multiple-battles-2.html.

8) Evans, D. P. (2020). COVID-19 and violence: A research call to action. BMC Women's Health, 20(1). https://doi.org/10.1186/s12905-020-01115-1

9) Evans, M. L., Lindauer, M., \& Farrell, M. E. (2020). A pandemic within a pandemic - Intimate partner violence during COVID-19. New England Journal of Medicine, 383(24), 2302-2304. https://doi.org/10.1056/nejmp2024046

10) Fegert, J. M., Vitiello, B., Plener, P. L., \& Clemens, V. (2020). Challenges and burden of the Coronavirus 2019 (COVID-19) pandemic for child and adolescent mental health: A narrative review to highlight clinical and research needs in the acute phase and the long return to normality. Child and Adolescent Psychiatry and Mental Health, 14(1). https://doi.org/10.1186/s13034-020-00329-3 


\section{COVID-19 and intimate partner violence: Women "trapped" in the "shadow pandemic}

11) Fisher, J., Languilaire, J.-C., Lawthom, R., Nieuwenhuis, R., Petts, R. J., Runswick-Cole, K., \& Yerkes, M. A. (2020). Community, work, and family in times of COVID-19. Community, Work \& Family, 23(3), 247-252. https://doi.org/10.1080/13668803.2020.1756568

12) Gan, G., Guevara, A., Marxen, M., Neumann, M., Jünger, E., Kobiella, A., Mennigen, E., Pilhatsch, M., Schwarz, D., Zimmermann, U. S., \& Smolka, M. N. (2014). Alcohol-induced impairment of inhibitory control is linked to attenuated brain responses in right fronto-temporal cortex. Biological Psychiatry, 76(9), 698-707. https://doi.org/10.1016/j.biopsych.2013.12.017

13) Hall, B. J., \& Tucker, J. D. (2020). Surviving in place: The coronavirus domestic violence syndemic. Asian Journal of Psychiatry, 53, 102179. https://doi.org/10.1016/j.ajp.2020.102179

14) http://pscipub.com/Journals/Data/JList/Advance in Agriculture and Biology/2015/Volume 4/Issue 3/2.pdf. (2015). Advance in Agriculture and Biology, 4(3). https://doi.org/10.15192/pscp.aab.2015.4.3.106113

15) Ibrahim, Z., Kuru-Utumpala, J., \& Goulden, J. (n.d.). (rep.). COUNTING THE COST: The Price Society Pays for Violence Against Women (pp. 1-33).

16) International Women's Health Coalition. The facts on child marriage. (2018, May 23). https://iwhc.org/resources/factschild-marriage/.

17) Kofman, Y. B., \& Garfin, D. R. (2020). Home is not always a haven: The domestic violence crisis amid the COVID-19 pandemic. Psychological Trauma: Theory, Research, Practice, and Policy, 12(S1). https://doi.org/10.1037/tra0000866

18) Lima, C. A., Alves, P. M., De Oliveira, C. J., De Oliveira, T. R., Barbosa, K. B., Marcene, H. C., \& De Oliveira, S. V. (2020). COVID-19: Isolations, quarantines and domestic violence in rural areas. SciMedicine Journal, 2(1), 44-45. https://doi.org/10.28991/scimedj-2020-0201-7

19) Lloyd, S. (1997). The effects of domestic violence on women's employment. Law Policy, 19(2), $139-167$. https://doi.org/10.1111/1467-9930.00025

20) Mannes, Z. L., Burrell, L. E., Bryant, V. E., Dunne, E. M., Hearn, L. E., \& Whitehead, N. E. (2015). Loneliness and substance use: The influence of gender among HIV+ Black/African American adults 50+. AIDS Care, 28(5), 598-602. https://doi.org/10.1080/09540121.2015.1120269

21) Meltzer, H., Doos, L., Vostanis, P., Ford, T., \& Goodman, R. (2009). The mental health of children who witness domestic violence. Child \& Family Social Work, 14(4), 491-501. https://doi.org/10.1111/j.1365-2206.2009.00633.x

22) Parker, R. (2021, February 4). How domestic violence affects women's mental health. The Conversation. https://theconversation.com/how-domestic-violence-affects-womens-mental-health-

104926\#: :text=How\%20violence\%20increases\%20the\%20risk,abuse\%2C\%20and\%20thoughts\%20of\%20suicide.

23) RachBeisel, J., Scott, J., \& Dixon, L. (1999). Co-occurring severe mental illness and substance use disorders: A review of recent research. Psychiatric Services, 50(11), 1427-1434. https://doi.org/10.1176/ps.50.11.1427

24) Rauhaus, B. M., Sibila, D., \& Johnson, A. F. (2020). Addressing the increase of domestic violence and abuse during the COVID-19 pandemic: A need for empathy, care, and social equity in collaborative planning and responses. The American Review of Public Administration, 50(6-7), 668-674. https://doi.org/10.1177/0275074020942079

25) Roesch, E., Amin, A., Gupta, J., \& García-Moreno, C. (2020). Violence against women during COVID-19 pandemic restrictions. BMJ, m1712. https://doi.org/10.1136/bmj.m1712

26) Sagar, R., \& Hans, G. (2018). Domestic violence and mental health. Journal of Mental Health and Human Behaviour, 23(1), 2. https://doi.org/10.4103/0971-8990.244924

27) Sharma, A., \& Borah, S. B. (2020). Covid-19 and domestic violence: An indirect path to social and economic crisis. Journal of Family Violence. https://doi.org/10.1007/s10896-020-00188-8

28) Su, Z., McDonnell, D., Roth, S., Li, Q., Šegalo, S., \& Wagers, S. (2021). Mental health solutions for domestic violence victims amid COVID-19: A review of the literature. Globalization \& Health, 17(1), 1-11.

https://doi-org.periodicals.sgu.edu/10.1186/s12992-021-00710-7

29) Tadesse, A. W., Tarekegn, S. M., Wagaw, G. B., Muluneh, M. D., \& Kassa, A. M. (2020). Prevalence and associated factors of intimate partner violence among married women during COVID-19 pandemic restrictions: A community-based study. Journal of Interpersonal Violence, 088626052097622. https://doi.org/10.1177/0886260520976222

30) UN Women. The economic costs of violence against women. (2016, September 21). https://www.unwomen.org/en/news/stories/2016/9/speech-by-lakshmi-puri-on-economic-costs-of-violence-againstwomen.

31) Usher, K., Bhullar, N., Durkin, J., Gyamfi, N., \& Jackson, D. (2020). Family violence and COVID-19: Increased vulnerability and reduced options for support. International Journal of Mental Health Nursing, 29(4), 549-552. 
COVID-19 and intimate partner violence: Women "trapped" in the "shadow pandemic

https://doi.org/10.1111/inm.12735

32) Usta, J., Murr, H., \& El-Jarrah, R. (2021). COVID-19 lockdown and the increased violence against women: Understanding domestic violence during a pandemic. Violence and Gender, 8(3), 133-139. https://doi.org/10.1089/vio.2020.0069

33) World Health Organization. (2013, October 20). Global and regional estimates of violence against women. World Health Organization. https://www.who.int/reproductivehealth/publications/violence/9789241564625/en/.

34) World Health Organization. (2021, March 9). Violence against women. World Health Organization. https://www.who.int/news-room/fact-sheets/detail/violence-against-women.

35) World Health Organization. (n.d.). Eastern Mediterranean Region. World Health Organization. http://www.emro.who.int/violence-injuries-disabilities/violence-news/levels-of-domestic-violence-increase-as-covid19-pandemic-escalates.html. 